\title{
THE INFLUENCE OF CUTTING PARAMETERS ON THE DYNAMIC STABILITY PERFORMANCE OF FINISHING CNC MACHINES
}

\author{
Daniel Popescu ${ }^{* 1}$ 四 \\ ${ }^{* 1}$ Faculty of Mechanics, University of Craiova, Romania \\ DOI: https://doi.org/10.29121/ijetmr.v7.i8.2020.748
}

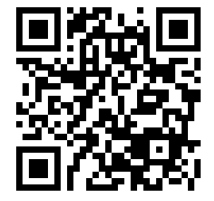

Article Citation: Daniel Popescu. (2020). THE INFLUENCE OF CUTTING PARAMETERS ON THE DYNAMIC STABILITY PERFORMANCE OF FINISHING CNC MACHINES. International Journal of Engineering Technologies and Management Research, 7(8), 50-55. https://doi.org/10.29121/ijetmr.v7 i8.2020.748

Published Date: 28 August 2020

Keywords:

Cutting Parameters

Dynamic Stability

Finishing

CNC Machines

Experimental Stand

\begin{abstract}
The paper describes the influence of the cutting regime parameters on the dynamic stability reserve of CNC finishing machines. For this purpose it is used an experimental stand comprised of transducers for measuring tool and workpiece rotation speeds, as well as a measuring device for the dynamic components of the cutting force (Ft, Fx). The processed materials are steel, bronze and cast iron. Finally there is presented the variation pattern of these parameters and their influence on the finishing process productivity.
\end{abstract}

\section{INTRODUCTION}

CNC finishing machines are one of the most significant cases for the treatment of vibration problems. This is due to the fact that surface finishing operations are usually solved by finishing [1].

Compared to conventional machining (with defined tools) where by choosing appropriately depending on the type of machine tool and the given operation, the cutting regimes, the process remains stable for a long time, when finishing, the process becomes unstable in a relatively short time. This causes the process to be interrupted in order to straighten the abrasive tool.

Among the rectification operations, the finishing process occupies an important place due to the special conditions in which it takes place [2].

In order to study the action of the parameters of the cutting regime on the dynamic stability reserve of the CNC finishing machine, we further reproduce the structure and connection schemes that are established between the main components in the technological process of finishing (fig. 1).

The experimental stand used for this purpose consists of transducers for measuring tool and workpiece speeds, as well as a sensor for measuring the dynamic components of the cutting force (Ft, Fx). Using for each measuring channel adequate connection schemes, at the level of the central computer, the variation of the two components $\mathrm{Ft}$, Fx is obtained according to the other parameters of the cutting regime, with the help of an interface for which special

(C) 2020 The Author(s). This is an open access article distributed under the terms of the Creative Commons Attribution License, which permits unrestricted use, distribution, and reproduction in any medium, provided the original author and source are credited. 
programs have been built such as: control of the acquisition board, processing of the measured signals, writing to files on the hard disk and displaying the signals on the screen.

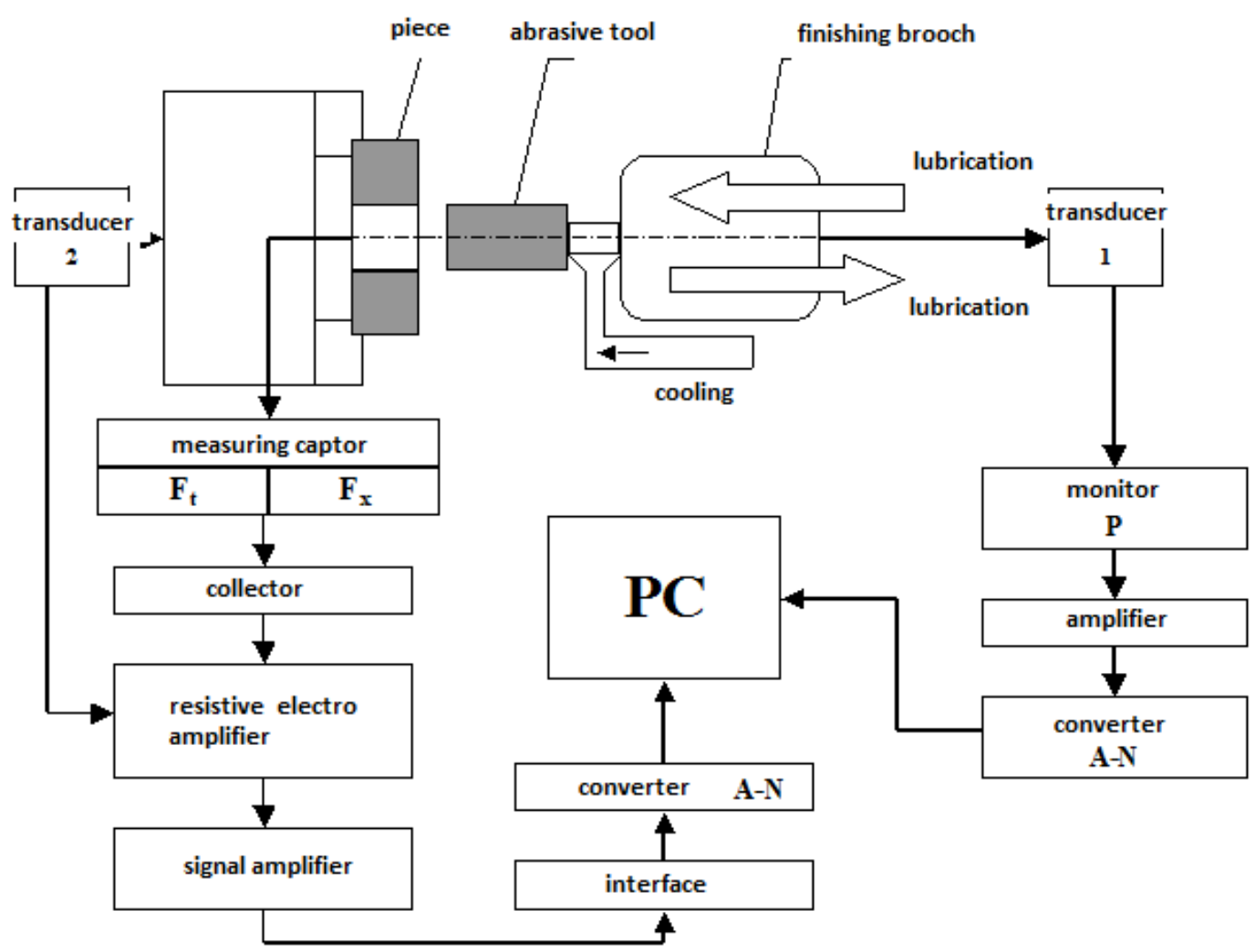

Figure 1: Real block diagram of the measuring chain used, tangential force, axial force

\section{DETERMINATION OF THE INFLUENCE OF CUTTING REGIME PARAMETERS ON THE DYNAMIC STABILITY OF FINISHING CNC MACHINE TOOL IN THE EVENT OF A STEEL TEST PART}

The variation diagrams of $\mathrm{F}_{\mathrm{t}}$ and $\mathrm{F}_{\mathrm{x}}$ are drawn for an optimal cutting regime corresponding to fig. 2, 3:

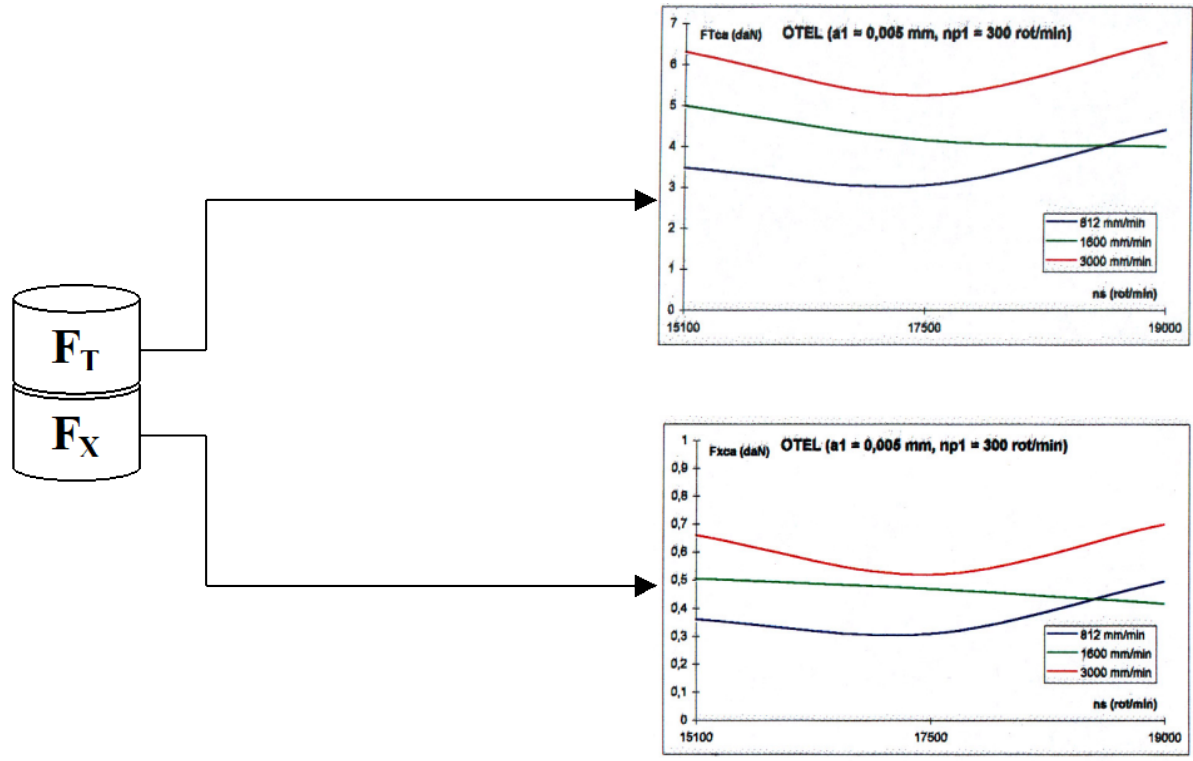


Figure 2: Analysis of the dynamic stability reserve for a given cutting regime when machining steel parts The modification of the circular advance of the part in the sense of its increase establishes the variations of the two parameters $\mathrm{F}_{\mathrm{T}}$ and $\mathrm{F}_{\mathrm{X}}$ as in fig. 3:

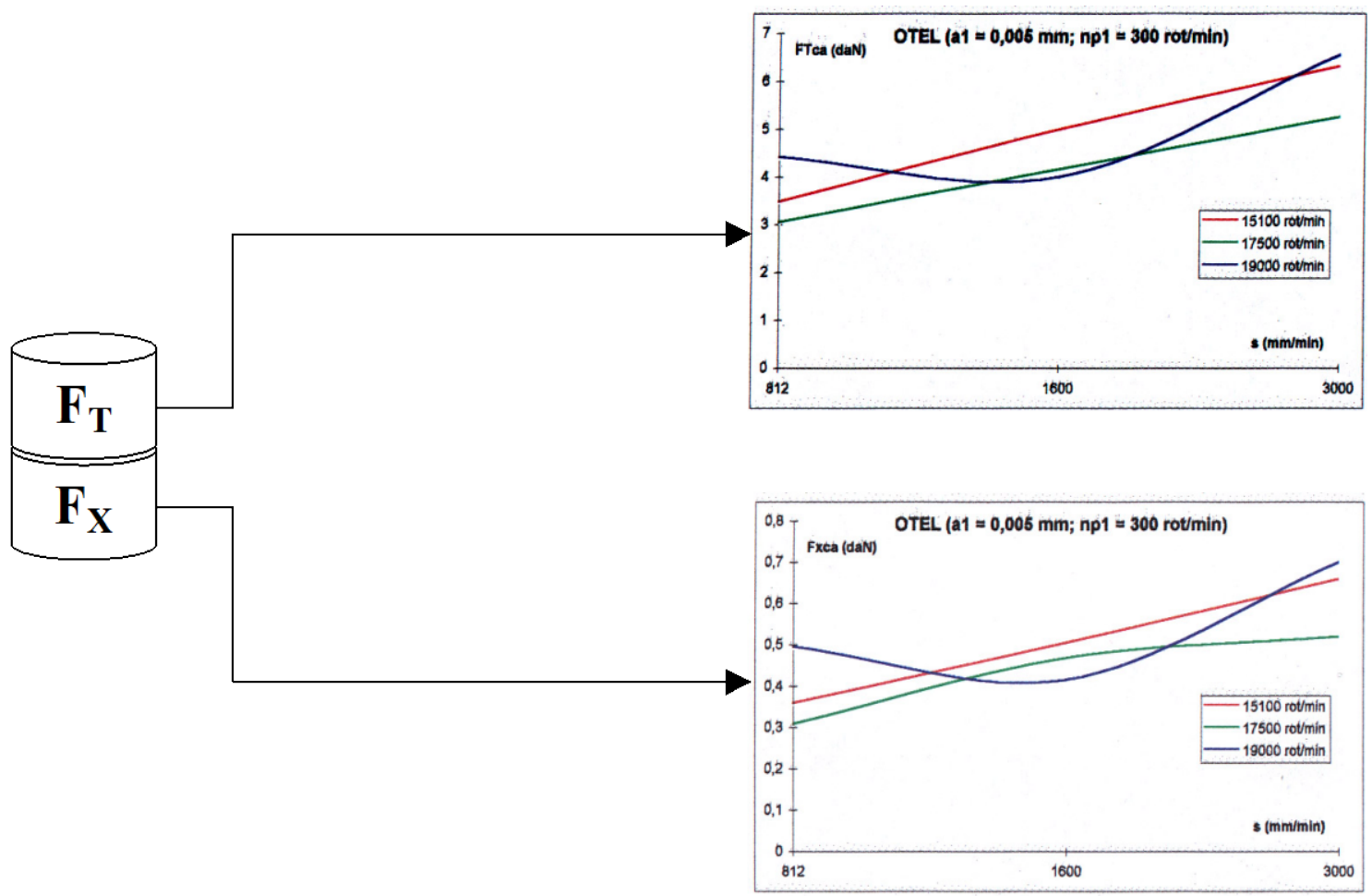

Figure 3: The influence of the circular advance on the dynamic stability reserve (steel parts)

By changing the cutting depth we have the following variation diagrams (fig. 4):

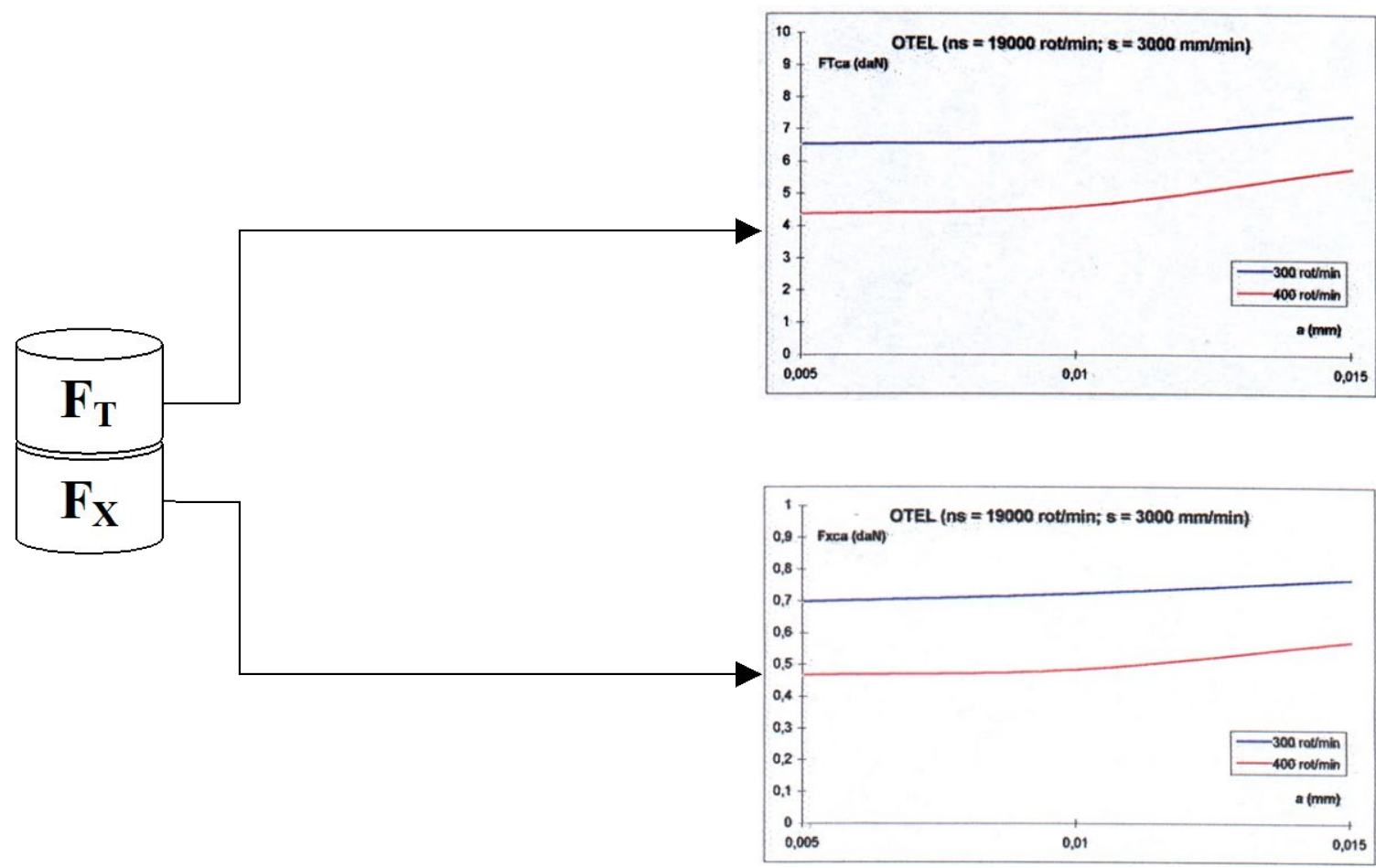

Figure 4: Influence of cutting depth on dynamic stability reserve (steel parts) 


\section{DETERMINATION OF THE INFLUENCE OF CUTTING PARAMETERS ON THE DYNAMIC STABILITY OF FINISHING CNC MACHINES IN THE CASE OF TEST PIECES MADE OF IRON AND BRONZE}

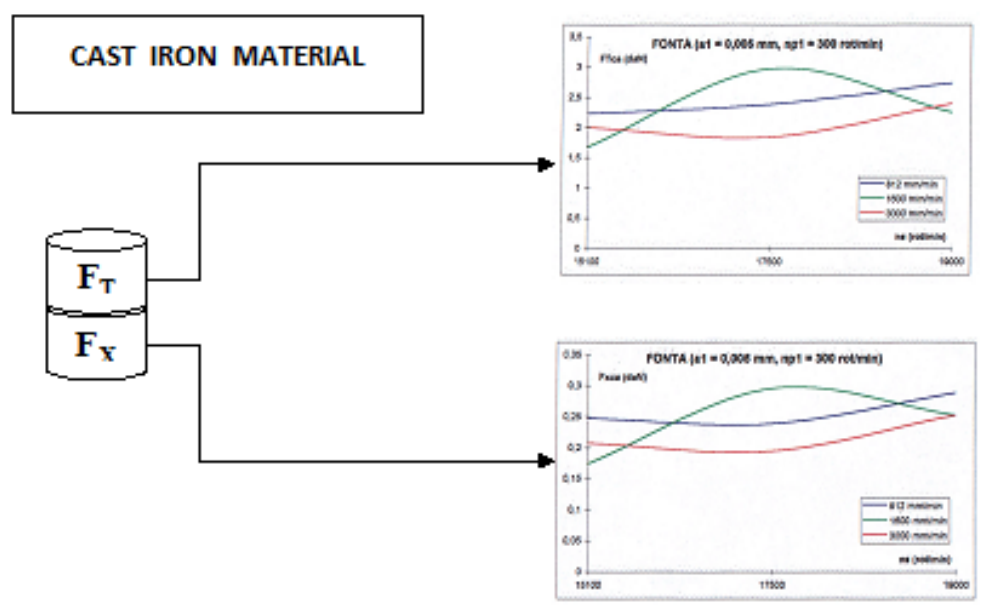

Figure 5: Analysis of the dynamic stability reserve for a given cutting regime when processing cast iron parts

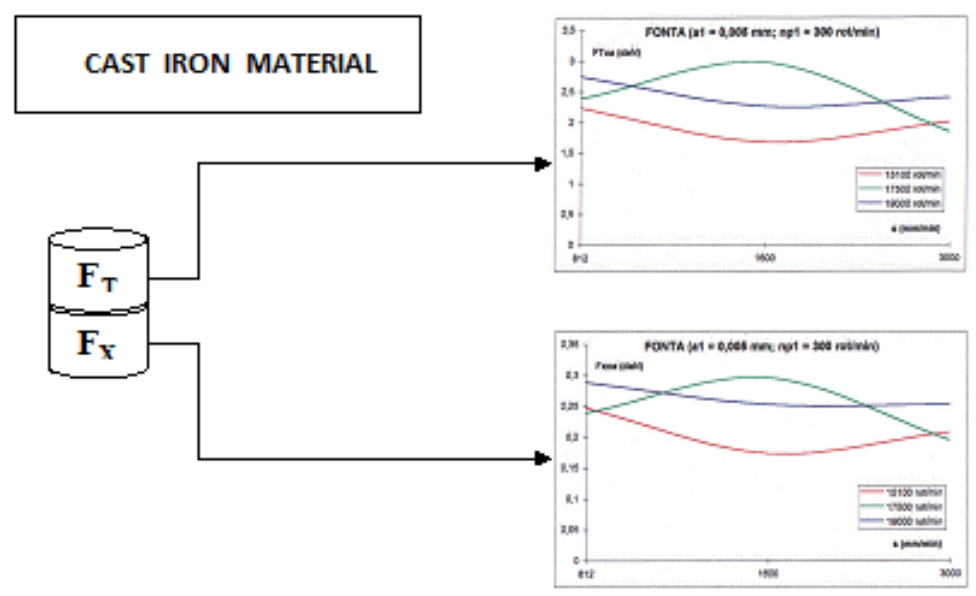

Figure 6: Influence of circular feed on dynamic stability reserve (cast iron parts)

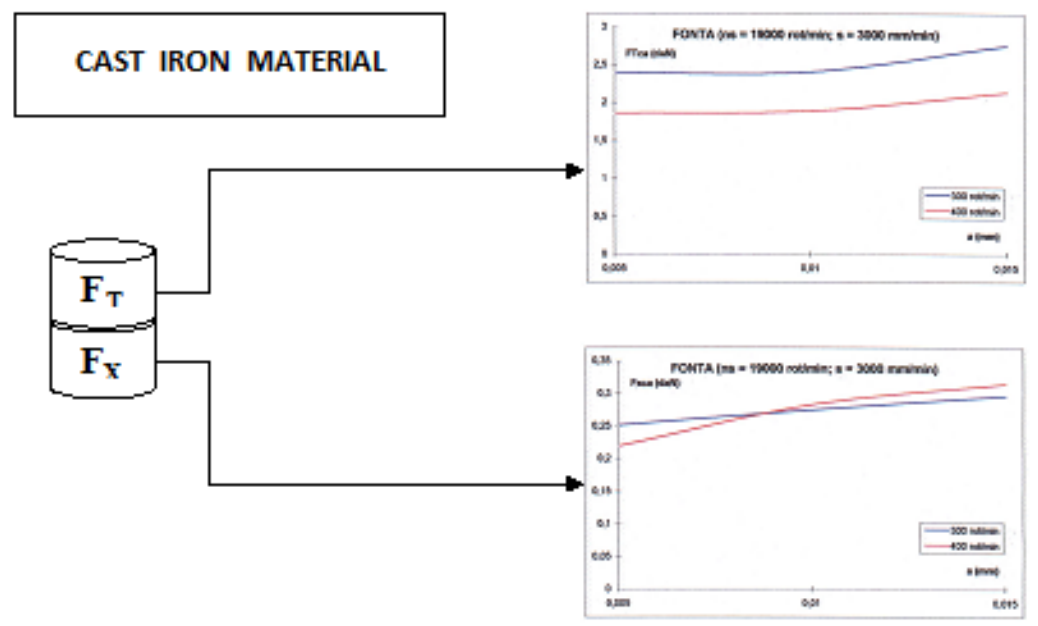

Figure 7: Influence of cutting depth on the dynamic stability reserve (cast iron parts) 
The Influence of Cutting Parameters on the Dynamic Stability Performance of Finishing CNC Machines

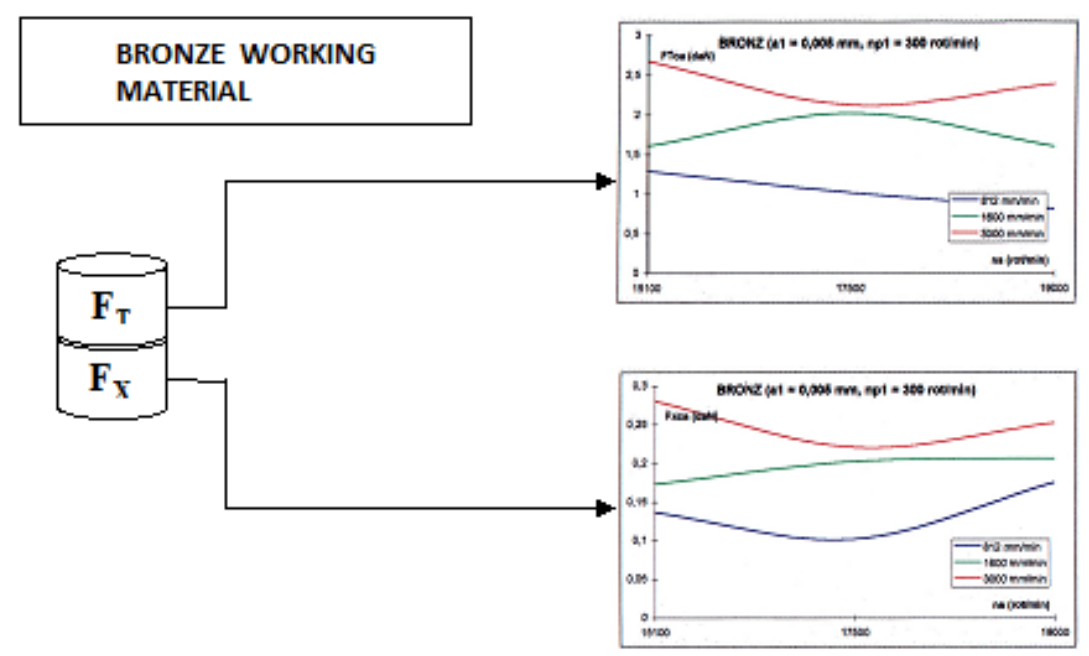

Figure 8: Analysis of the dynamic stability reserve for a cutting regime given to the processing of bronze parts

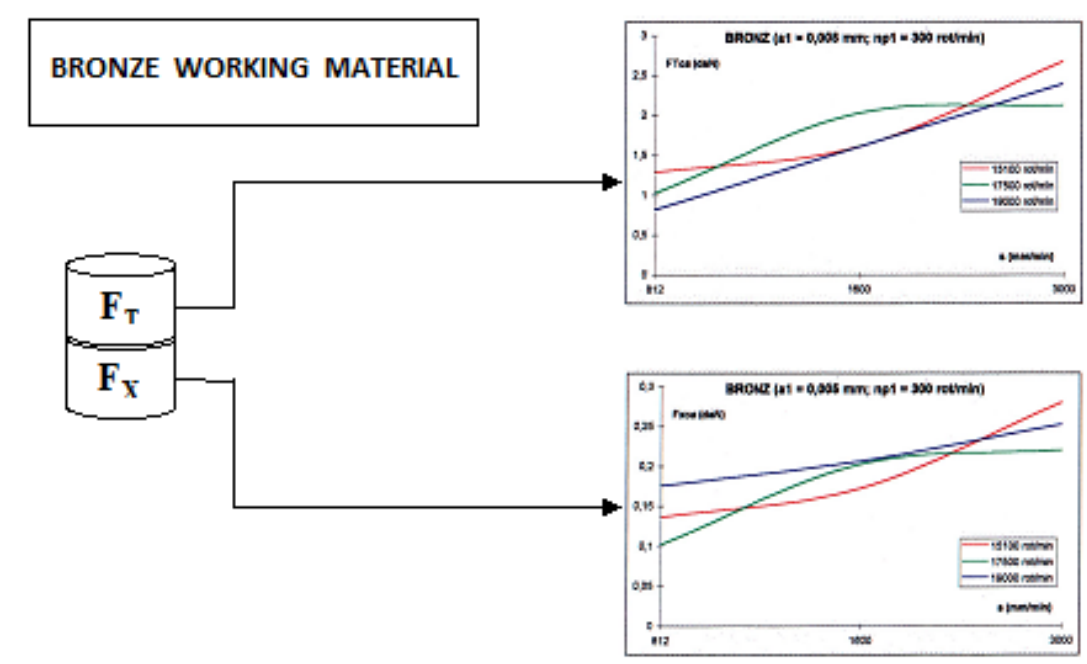

Figure 9: The influence of the circular advance on the dynamic stability reserve (bronze parts)

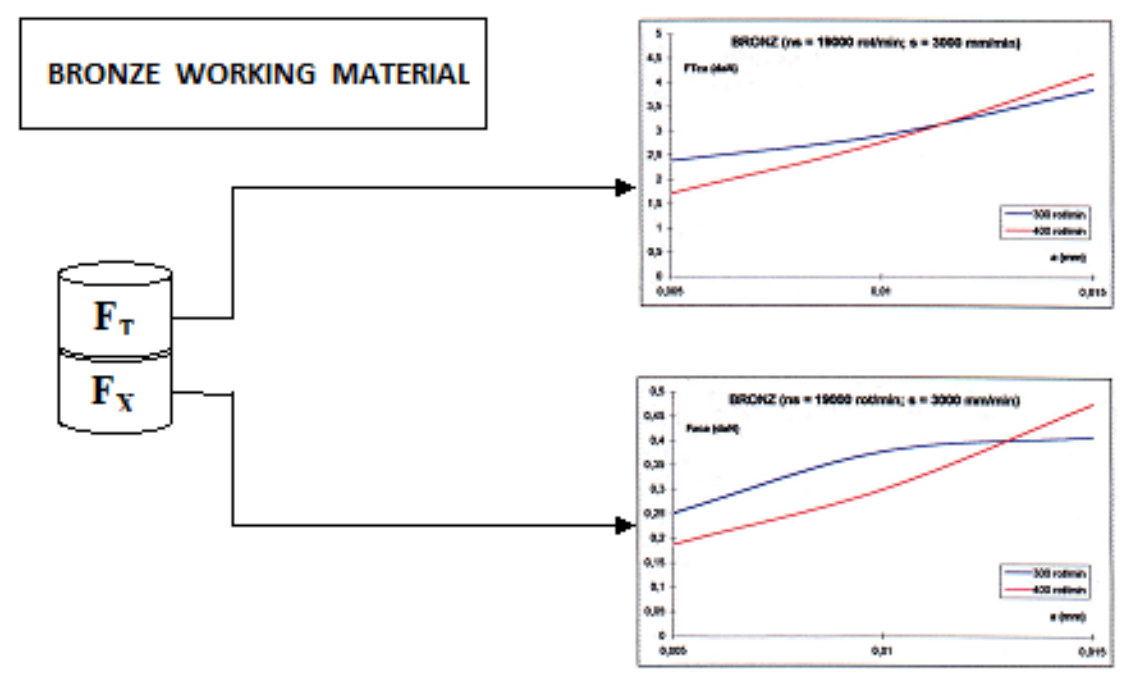

Figure 10: Influence of cutting depth on dynamic stability reserve (bronze parts) 
Daniel Popescu

\section{CONCLUSIONS}

From the analysis of the evolution of the components of the cutting forces it is found that the highest values occur in the case of steel finishing, while in the case of finishing cast iron and bronze they are significantly reduced, the measured values being relatively close [3].

Increasing the cutting depth has a negative effect on the dynamic stability reserve of the finishing machine.

The feed rate and the main cutting speed admit value ranges in which their action is generally positive in a middle range of the cutting speed $\mathrm{n}_{\mathrm{S}}=17500 \mathrm{r} / \mathrm{m}$ and in a higher range of advance variation $\mathrm{f}_{2}=1600 \mathrm{~mm} / \mathrm{min}$ and $\mathrm{f}_{3}=3000 \mathrm{~mm} / \mathrm{min}$.

The best stability reserve was obtained for small cutting depths $\mathrm{a}_{\mathrm{p} 1}=0.005 \mathrm{~mm}$, average advances $\mathrm{f}_{2}=1600 \mathrm{~mm}$ $/$ min and a circular advance of the part increased to $\mathrm{n}_{\mathrm{P} 2}=400 \mathrm{r} / \mathrm{m}$.

Usually if the increase of the stability reserve is imposed by the increase of the advance, of the main cutting speed or of the circular advance of the part, these do not always present effective measures to increase the stability [4], [5], [6].

In the case there is no direct kinematic connection between the main kinematic chain and the feed kinematic chains, so that the speed of the main shaft is independent of the feed size, so that as the speed of the main shaft increases, the feed rate remains constant, the feed decreases, i.e. the positive influence of the increase of the main cutting speed is partially compensated by the negative effect of the corresponding decrease of the longitudinal or circular advance thus canceling the effectiveness of the adopted measure, therefore it is necessary that in these cases, with the increase of the main axis speed, the same direction and the longitudinal and circular advance of the part, which is possible in the case of machine tools provided with adaptive controls [2].

Due to these limitations regarding the measures of increase of $n_{S}$ and $f$ or $n_{P}$, in order to ensure the dynamic stability, it remains certain the decrease of the cutting depth, following that the loss of productivity of the technological operation, caused by the variation of the cutting depth, is partially avoided by the corresponding increase in the circular feed of the part, which generally leads to an increase in the stability of the machine [1].

\section{SOURCES OF FUNDING}

None.

\section{CONFLICT OF INTEREST}

None.

\section{ACKNOWLEDGMENT}

None.

\section{REFERENCES}

[1] Barmin, B.P., Vibrations and Regimes of Resistance, Moscow, 1972.

[2] Popescu, D., Research on the influence of the parameters of the cutting regimes on the reserve of dynamic stability of the internal grinding machines, Research contract, Beneficiary MCT.

[3] Popescu, D., Theoretical and experimental contributions regarding the improvement of the processing precision for the internal grinding machines, p. 115-122, Doctoral thesis, Univ. Pole. Bucharest, 1999.

[4] Chen, C.H., Wang, K.W. and Shin Y.C. 1994. An Integrated Approach Toward the dynamic Analysis of HighSpeed Spindles - System Model. J. Sound Vibration, 506-512.

[5] Chen, C.H., Wang, K.W. and Shin, Y.C. 1994. Dynamics Under Moving End Load. J. Vibrations Acoustics 116, 514-522.

[6] Moraru, V. and Ispas, C. 1982 Vibrations and Machine Tools Stability. EDP. 